\title{
Turismo y gentrificación: pistas teóricas sobre una articulación ${ }^{1}$
}

\author{
Daniel Hiernaux² y Carmen Imelda González ${ }^{3}$
}

\begin{abstract}
RESUMEN
El crecimiento del turismo urbano obliga a una reconceptualización del mismo. La primera parte del trabajo se orienta a una teorización del turismo desde diversas perspectivas conceptuales: interés en el turista, sus prácticas, su situación como individuo-actante, como productor del espacio turístico, entre otras orientaciones. En la segunda parte se analiza la relación entre el turismo urbano y la gentrificación; se establece que la gentrificación en los centros históricos de América Latina se debe más a su "turistificación" y a las políticas urbanas de los gobiernos locales, que a procesos basados en la acción de individuos gentrificadores de clase media. Se concluye reafirmando la fuerte aunque peculiar relación entre las nuevas modalidades de turismo urbano y la gentrificación.
\end{abstract}

Palabras clave: Turismo, gentrificación, ciudad.

\begin{abstract}
The growth of urban tourism requires a reconceptualization of the same. The first part of this essay is oriented to its theorization from various conceptual perspectives: interest in the tourist, their practices, their situation as an acting person, as a producer of the tourism space, are some of the various viewpoints considered. The second part, analyzes the relationship between urban tourism and gentrification; we state that the gentrification of historical downtown neighborhoods in Latin America is more the result of their "turistification" and the urban politics of local governments, than of processes based on the actions of the middle class gentrifiers. The conclusion confirms the strong but peculiar relationships between new types of urban tourism and gentrification.
\end{abstract}

Key words: Tourism, gentrification, city, urban.

1 Artículo recibido el 11 de noviembre de 2013 aceptado el 11 de marzo de 2014 y corregido el 30 de mayo de 2014.

2 Facultad de Ciencias Políticas y Sociales, Universidad Autónoma de Querétaro (México).

E-mail: danielhiernaux@gmail.com

\footnotetext{
3 Facultad de Ciencias Políticas y Sociales, Universidad Autónoma de Querétaro (México).

E-mail: carmenimelda@gmail.com
} 
El turismo internacional ha logrado un desarrollo particularmente relevante desde la segunda guerra mundial. Se observa -con cierta sorpresa- que, a pesar de las crisis y las condiciones de inseguridad que afectan a muchos destinos apreciados por los turistas, el turismo internacional mantiene un crecimiento muy significativo: de 3 a $4 \%$ para 2013 según estimaciones recientes de la Organización Mundial del Turismo. En este panorama, las ciudades y en particular ciertas áreas arquetípicas de las mismas, se han convertido en espacios de consumo colectivo masivo, tanto para el consumo material como simbólico y atraen cada más turistas. No existen estadísticas detalladas por segmentos de turismo a nivel mundial, pero los estudios específicos sobre diversos casos de turismo nacional, muestran que una parte creciente de la demanda turística se orienta hacia las ciudades (Hiernaux, 2005).

Esta evolución puede explicarse de varias maneras. Una de ella es la fragmentación de los tiempos vacacionales: se observa una creciente preferencia de los turistas hacia desplazamientos de corta duración en vez de estancias largas, las cuales privilegian los destinos costeros o de montaña. Parte de la justificación de esta situación encuentra sus raíces en las nuevas formas de organización del trabajo que permiten mayor flexibilidad en la distribución de los tiempos laborales y de vacaciones $y$, en buena manera, en el descenso de la tasa de natalidad que facilita los desplazamientos de corta duración, en diversos momentos del año y no exclusivamente en los largos periodos de vacaciones escolares. Ambas situaciones privilegian un turismo de estancias cortas y, por lo general, hacia áreas urbanas.

El turismo urbano obedece a diversas motivaciones, desde el aprovechamiento del patrimonio cultural de la ciudad (Jansen-Verbeke, 1998), su diversidad étnica (Hoffman et al., 2003), sus equipamientos culturales y hasta la destrucción de las huellas materiales de su historia por motivos de guerras y bombardeos (el llamado turismo de lamentación o "mourning tourism"; véase White \& Frew, 2013).

Al hacer un recuento de publicaciones recientes, se puede mostrar la predominancia de los estudios de caso, sea de las trayectorias de ciertas ciudades como destinos turísticos en auge, sea de ciertos segmentos particulares del turismo urbano: el turismo gay, el turismo étnico, el turismo cultural, entre otros. La particularidad de la mayor parte de estos trabajos, es la escasez de referencias teóricas y la abundancia de materiales específicos que, más que abonar a la producción de una teoría del turismo urbano, complican en muchas ocasiones la posibilidad de elaborar una síntesis.

En las páginas que siguen nos abocaremos, en un primer tiempo, a trazar líneas preliminares hacia una teorización del turismo urbano y, en un segundo tiempo, se buscará establecer puentes entre lo que se ha producido sobre la gentrificación y el fenómeno del turismo urbano.

\section{Hacia una teorización del turismo en la ciudad}

Los aportes seminales de Mullins sobre turismo y urbanización (Mullins, 1991, 1994) desbrozaron unas primeras pistas para entender la relación entre el turismo y la urbanización. Sus trabajos sobre la Costa de Oro Australiana aportaron por lo menos dos anotaciones de interés para nuestros planteamientos. La primera es que el crecimiento metropolitano no puede ser estudiado sin tomar en cuenta los efectos del turismo sobre el mismo. En segundo lugar, y aunque el caso estudiado es más bien singular como lo anotan atinadamente Fainstein y Gladstone, Mullins evidencia el crecimiento de una pequeña burguesía ligada a estos procesos turísticos (Fainstein \& Gladstone, 1999: 24; Mullins, 1994). Esta apertura es útil para Ilamar la atención sobre la transformación de la estructura de clases en el entorno urbano, como resultado del turismo.

En esta mismo línea y siempre desde los aportes anglosajones, fueron fundamentales los esfuerzos realizados bajo la dirección de Dennis Judd, Susan Fainstein y Lilly Hoffman con financiamiento de la Fundación Ford a través del Consejo de Ciudades Europeas, para montar el grupo de investigación "International Tourism Research Group" (ITRG) en 1998, en el cual se interrogó colectivamente 
y a partir de experiencias internacionales muy diversas, la relación del turismo y la ciudad (Gladstone \& Hoffman, 1998). Además de tres libros (Judd \& Fainstein, 1999; Hoffman et al., 2003; Judd, 2003), el artículo de Judd en la revista chilena Eure (Judd, 2003), marcó un hito en esta discusión y movió los estudios del turismo hacia una mejor comprehensión de su articulación con el espacio y lo urbano. Fainstein y Judd, en las conclusiones del libro que coordinaron, proponen una tipología sugestiva de tres modelos de ciudades turísticas: Las ciudades-destino turístico (tipo Cancún) aquellas que Mullins considera como ciudades creadas ad hoc para el turismo por medio de un proceso de "urbanización turística" ("tourism urbanization" según Mullins, 1991); las ciudades de turismo histórico, las cuales obviamente tendrán mayor relevancia desde la perspectiva de nuestra correlación propuesta entre turismo y gentrificación; y, finalmente, las ciudades reconvertidas al turismo, entre otros por nuevos emprendimientos turísticos, como museos, acondicionamientos de frente fluviales, infraestructuras deportivas, etcétera (Fainstein \& Judd, 2003: 262-267).

Otra aportación importante de estas obras es la referencia a la ciudad desde la cultura y en particular, el hecho de hablar de "ciudades como espacios de juego" ("cities as places to play", Fainstein \& Judd, 1999: 260272). Esta propuesta va además asociada con lo que se considera un parque temático, lo cual los autores trabajan de manera aislada y no desde los espacios urbanos. Todas estas reflexiones de los autores se insertan en una corriente analítica que promueve una renovada lectura del turismo y cuya obra paradigmática es, sin lugar a duda, "The Tourist Gaze" de John Urry (Urry, 2002) el cual colabora además a una de las obras colectivas del ITRG con un artículo particularmente interesante sobre los sentidos y la ciudad ("Sensing the City"), incluido en Urry (1999: 71-86). Por otra parte, los trabajos de John Urry (2002) y David Crouch (1999) entre otros, han interpelado el estudio tradicional del turismo desde perspectivas culturales interesantes, toda vez que se asocian a las corrientes posmodernas de la geografía contemporánea. Destaca la importancia de la movilidad entendida más allá del desplazamiento como tal de individuos o personas, sino esencialmente como una fuerza dinamizadora que nos obliga a una nueva conceptualización de la ciudad misma, como lo ha afirmado claramente el sociólogo urbano belga, Jean Remy.

El artículo mencionado de Judd en Eure resume varios de los hallazgos de los seminarios de ITRG y de las publicaciones posteriores ya citadas y da varios pasos más allá que abren perspectivas interesantes para el estudio del turista, particularmente en los centros históricos. El autor analiza el nuevo discurso Ilamado posestructuralista o posmoderno, cuyo relato sobre los espacios turísticos incluye a estos últimos en una categoría de enclaves turísticos, donde reinaría la manipulación y vigilancia del turista y una tematización creciente articulada con modelos de consumo asociados a tendencias globales manipuladas por las grandes empresas del ocio como Disney (Judd, 2003: 52). A partir de las experiencias de las ciudades europeas, advierte que en ciertas ocasiones los planificadores intentan construir espacios turísticos que puedan satisfacer al mismo tiempo los residentes tanto como los visitantes y que este espacio turístico se encuentra concentrado en las áreas donde prevalece un patrimonio histórico importante (Judd, 2003: 57-58). Nuevamente retoma el tema de las clases sociales asociadas con esa nueva demanda de turismo, en particular a partir de Lloyd (2002) y de los primeros trabajos de Richard Florida (2002). Obviamente que, en este caso, las reflexiones sobre clases sociales son muy distintas de las de Mullins, ya que teñidas por un fuerte acento posmoderno. La posición tomada por Judd es particularmente relevante al pensar que no puede existir un modelo perfecto de enclave donde el turistavisitante estuviera sometido a reglas estrictas sobre qué tiene que visitar o consumir y que existe la posibilidad de una actitud más abierta y libre del Ilamado "pos-turista", es decir aquel que no solo reproduce las reglas implícitas del viaje pautado sino que ejerce su propia iniciativa.

Habrá que notar, además, que en el marco de los dos eventos de Amsterdam y de Barcelona del grupo ITRG, se observó una fuerte diferencia de opinión entre anglosajones y europeos sobre lo que es el turismo, los objetos turísticos, etcétera. El primer grupo apostando más a una definición del turismo y de la cul- 
tura sustentada en las industrias correspondientes mientras que los segundos preferían seguir la pista de adjudicar otras cualidades al turismo, a partir de sus dimensiones sociológicas y, además, socioespaciales (Véase la diferencia entre los trabajos en Judd y Fainstein, 2003). Vale notar que estas aperturas conceptuales permiten colocar el estudio del turismo en una línea de análisis sobre el espectáculo que fue descubierta y sugerida de manera atractiva en la obra de Henri Lefebvre (1974 muy particularmente) y de Guy Debord y la Internacional Situacionista (Debord, 1995).

Otra línea conceptual relevante para nuestro propósito es la que se origina en la obra del equipo M-I-T, "Mobilité, Itinéraires et Territoires" que ha reunido numerosos estudiosos del turismo del ámbito francófono alrededor de Remy Knafou como nodo dinamizador, y que también aportó elementos interesantes a partir del momento en que recentró el estudio del turismo en los turistas (Equipe MIT 2002; 2005; 2011), y no en las infraestructuras o las dimensiones exclusivamente "commodificadas" del mismo, como suele pasar en numerosos trabajos particularmente anglosajones (Pearce, 1999, por ejemplo, sobre el caso de los "distritos turísticos" de París).

Como señalado más arriba, una particularidad del trabajo de Grupo MIT ha sido la de revalorizar el turista sobre el turismo. Esto se deriva de su planteamiento de pasar de una geografía del turismo a una aproximación geográfica del turismo (Equipe MIT, 2002: 293). Si bien esta propuesta se construye a partir de un andamio de textos francófonos, los autores reconocen los aportes hechos por dos autores anglosajones particularmente destacado, Cohen (1979) y MacCannell (2003), que pueden ser considerados como pioneros en el desarrollo de una reflexión sobre el turismo basada en el turista como persona, aun si sus bases epistemológicas son muy distintas: Cohen situándose en una línea tanto sociológica como incluso fenomenológica, y MacCannell con una perspectiva crítica de cuño marxista, aunque sin rigideces. En este sentido, la propuesta de recentrarse sobre el turista, coincide plenamente con el planteamiento de diversos geógrafos como Vincent Berdoulay (2012a) que reclaman una geografía basada sobre la experiencia del individuo. Esta perspectiva deja de asumir que la preferencia debe ser acordada al lugar, para valorizar las prácticas turísticas como prácticas socioespaciales específicas. Pensamos que es mediante una perspectiva de este tipo que se puede analizar, de forma más certera, la relación entre el turismo urbano y la gentrificación: anticipamos de esta manera, que la gentrificación producida por el turismo no es solamente un cambio en las actividades o los residentes (vistos como grupo, o sea, genéricamente, los "turistas") sino también la producción de un conjunto de interacciones entre turistas y residentes permanentes que opera no solo en el plano material sino también y quizás sobre todo, en el plano simbólico.

Antes de proseguir, resulta útil plantearse una definición de partida de la gentrificación. La definición más aceptada es la que considera que es un proceso de desplazamiento espacial de una población de menor perfil económico por otra de mayores ingresos y capital cultural (véase Lees et al., 2008). Esta definición, si bien responde a los elementos claves (el reemplazo de población y el diferencial de potencialidades de los grupos sociales), dista de ser suficiente como lo veremos posteriormente.

Estos planteamientos constituyen las principales referencias teóricas de nuestro trabajo que busca repensar el turismo como un proceso que modifica las formas de habitar la ciudad. También en este caso, es prudente definir otra posición que asumimos y que se articula con diversos aportes conceptuales. En este caso, el "habitar" lo repensamos en la línea abierta por diversos autores como Berque (2007), de Radkowski (2002), (2012b), Paquot et al. (2007), Stock (2007), y otros. Una primera dimensión de estas aportaciones, es la que remite al fenómeno de habitar como un proceso cultural (Giglia, 2012). El "Habitar" conceptualizado desde la filosofía heiddegeriana, es entonces un proceso de edificación y cuidado del espacio, como forma de ser en el mundo (el Dasein de Heidegger, donde el prefijo Da implica una dimensión espacial del habitar, de tal suerte que la traducción considerada como más adecuada es "ser-en-el-mundo"). También se replantea al habitar no solo como la ocupación de un alojamiento de manera estable, sino desde perspectivas nuevas, tanto temporales -por ejemplo que asumen el papel de lo efímero en el habitar- como espaciales a través 
del concepto de "politopía" (propuesto por Mathis Stock, 2007) o pluriresidencia. Este concepto introduce la idea de que, en ciertas comunidades tradicionales (las que mantienen la trashumancia, por ejemplo) pero esencialmente en las posmodernas, el habitar no es forzosamente ligado a una sola residencia. El fenómeno de la segunda residencia que ha literalmente explotado en los últimos años en América Latina ejemplifica bien esta politopía creciente de las sociedades contemporáneas (Hiernaux, 2010, 2012a). También los casos de quienes viven con una movilidad permanente entre varias ciudades por razones de trabajo y gracias a los progresos considerables de los medios de transporte (Tarrius, 1992). Finalmente, aquellas personas que construyen su habitar a partir de desplazamientos frecuentes para los cuales el ocio es una motivación significativa.

En esta perspectiva, el turismo en un centro urbano adquiere un sentido renovado: el turista no es solamente un "visitante" efímero que recorre espacios, sino un individuo que forma parte de una categoría particular de habitantes que también producen la ciudad día a día, a través de sus prácticas socioespaciales en un escenario ya ocupado por otros grupos como residentes permanentes $y / 0$ trabajadores en el espacio, entre otros, y como habitantes que ejercen sus propias prácticas. Este aporte es esencial desde nuestro punto de vista, para evitar un análisis del turismo en los centros históricos desde posiciones esencialmente estructuralistas o neoestructuralistas como aquellas desarrolladas por la geografía tradicional del turismo (al respecto véase Hiernaux, 2006).

\section{Turismo y gentrificación en los centros históricos}

No pretendemos, en esta tercera y última parte del ensayo, construir una teoría de la gentrificación, sino intentar articular las reflexiones anteriores sobre el turismo urbano con los avances observados en el estudio de la gentrificación.

Aceptamos el planteamiento hecho por Lees et al. (2008) que la gentrificación obliga a una relectura de lo urbano, particularmente de la forma como se reconstruyen los espa- cios centrales de las ciudades. Asimismo, asumimos que lo que se ha producido desde el mundo anglosajón no forzosamente refleja los procesos en curso en otros ámbitos, en especial el mundo urbano latinoamericano, locus de nuestro interés en este ensayo (Janoschka et al., 2013). Por ende, intentaremos reconstruir una explicación genuina -una interpretación propia- de la relación compleja que se teje entre el turismo urbano y la gentrificación, haciendo mano de los aportes conceptuales que mostramos como relevantes en las páginas anteriores y otras consideraciones de utilidad que emanan del corpus de trabajos existentes sobre la gentrificación. En particular queremos señalar que estamos conscientes de la dominación del pensamiento anglosajón sobre la temática, por lo que voluntariamente estamos tratando de articular propuestas conceptual-metodológicas originadas en varias cuencas lingüísticas. Sugerimos la necesidad de una descolonización de nuestras referencias, que pasa -en nuestra opinión- por su relectura desde el ámbito latinoamericano, su hibridación por medio de su mezcla con aportes de otras cuencas lingüísticas y, finalmente, la desarticulación de su tufo centralista mediante su fusión en el análisis de los casos latinoamericanos ${ }^{4}$.

Quizás el punto de anclaje más fuerte con las realidades latinoamericanas es el reconocimiento de que son escasos, en el entorno subcontinental, los casos genuinos de gentrificación en los cuales se pudiera observar una reapropiación por grupos de ingreso medio o alto de espacios degradados. Asimismo, los procesos de recambio de población y sobre todo de reapropiación social de espacios degradados en América Latina, tienen esencialmente curso en los centros históricos de

\footnotetext{
4 La tendencia a recuperar acríticamente conceptos formados bajo otras latitudes es definitivamente un resultado de un cosmopolitismo hegemónico que solo sirve los intereses de quienes se reapropian estos conceptos para una "cocina" propia. Como lo subraya Boaventura de Souza Santos, las ciencias sociales actuales requieren de una "resistencia epistemológica", la cual podría llevar a asumir un posición que denomina de "cosmopolitismo subalterno", es decir una posición que anhela alcanzar una nueva modalidad de cosmopolitismo de resistencia aunque, a la vez, de reapropiación de ciertas condiciones favorables que ofrece la postura cosmopolita (Da Souza, 2009: 179-181)
} 
ciudades $y$, con mucho menor relevancia, en áreas rurales como lo han demostrado $\mathrm{Na}$ tes y Raymond en otros entornos (2006). De paso habrá que notar que se ha manifestado escaso interés académico hacia esta forma de gentrificación rural; para el caso mexicano, las reflexiones de las autoras mencionadas parecerían cobrar relevancia frente a la política pública de desarrollar "Pueblos Mágicos"5.

Las reflexiones que elaboramos a continuación se sitúan entonces en el contexto más específico de los centros históricos latinoamericanos, aunque con la pretensión de adquirir un carácter de mayor generalización.

Una primera constatación gira en torno a la trayectoria temporal de los centros históricos: la mayor parte de ellos han pasado por una etapa colonial a lo largo de la cual existió una cierta convivencia o mezcla de grupos sociales, aunque las convenciones sociales -las reglas escritas y las normas tácitas- imponían que la presencia de grupos distintos en un mismo espacio no desemboque en mayores contactos entre los mismos. El abandono de los centros por parte de los grupos más pudientes puede, con toda evidencia, fecharse con el crecimiento urbano por lo general ligado a la intensificación de la actividad económica de la ciudad y las fuertes migraciones consecuentes campo-ciudad. Sin embargo, al no darse un traslado muy alejado de las clases pudientes del centro de las ciudades, después de varias décadas su propio hábitat se encuentra integrado a lo que se considera ahora como "Centro Histórico". En otros términos, la calificación de centro histórico recubre actualmente tanto el viejo casco fundacional y la extensión de la ciudad colo-

\footnotetext{
5 El Programa de Pueblos Mágicos del gobierno federal mexicano, inició en 2001, y consiste en fomentar una mejoría de las condiciones de habitabilidad de algunas localidades menores a lo largo del país (83 localidades seleccionadas hasta la fecha) para incentivar su desarrollo turístico a partir de la valorización de un potencial sustentado en lo "mágico". Véase una aproximación para el caso específico de Alamos (2010) y para Mineral de Pozos en Hiernaux, 2014 (en prensa). Un grupo amplio de investigadores mexicanos está en la actualidad desarroIlando proyectos sobre el tema y se puede esperar tener resultados de un abanico de estudios de casos que permitirán una evaluación significativa de este programa oficial y de sus resultados.
}

nial o "ciudad patricia" (en términos de José Luis Romero, 1976) sino también los espacios sumados que alguna vez fueron suburbanos y donde se asentaron los grupos pudientes en esa primera etapa de reestructuración morfológica de las ciudades latinoamericanas.

El abandono consciente de las áreas centrales a las clases populares fue acompañado, en un primer tiempo, por la persistencia de un acceso de los grupos pudientes a los centros por cuestiones ligadas al comercio, los trámites burocráticos o diversas actividades ligadas al ocio. Pero claramente, desde los años cincuenta, la desconcentración urbana de las actividades administrativas, comerciales y de servicios, así como las de ocio propiciaron un mayor aislamiento entre los grupos sociales y un desinterés de los grupos pudientes hacía las áreas centrales. El carácter fuertemente popular de las áreas centrales, el hecho de que mantuviera una vida activa a través del empleo formal y sobre todo informal, agregándose a ello cierto nivel de inseguridad propició una barrera mental que parecería haber impedido la eclosión de procesos de gentrificación tales como los descritos por la literatura anglosajona y francófona: estos mundos apartes regidos por reglas internas, eventualmente con diferencias étnicas sobrepuestas sobre desigualdades de estatuto, no se ofrecían mutuamente muchas condiciones de encuentro.

Lo anterior explicaría entonces que lo que se ha observado hasta ahora como fenómenos asociables a una "gentrificación" en América Latina encuentre su origen en otros procesos que a continuación analizaremos. El primero es sin lugar a duda la voluntad de los estados nacionales y de las administraciones locales de retomar el control de espacios fuera del ámbito del mercado capitalista abierto y normado. Reducir la informalidad implica también intentar eliminar grupos de poder difícilmente controlables por el sistema. El Estado, central o local, a través de acciones tendientes a regular los espacios centrales y volverlos atractivos, emprende políticas directamente a tono con la gentrificación.

El segundo proceso y sin duda el más importante, es sin lugar a duda el potencial de los centros históricos desde la perspectiva del desarrollo económico en un contexto de crisis 
del modelo urbano industrial. El multicitado artículo de Michael Porter en "Harvard Business Review" (1995), si bien remite a contextos desarrollados, no deja de ser pertinente para el ámbito latinoamericano. En cierta manera contribuye al derrumbe del muro mental antes mencionado entre grupos burgueses y localizaciones centrales, por lo menos desde una perspectiva de negocios. Para nuestros países, es evidente que un interés empresarial solo puede tener éxito si es precedido por una intervención estatal destinada a regular el funcionamiento de los centros históricos. Es efectivamente lo que ocurrió en varias ciudades, en parte con referencia a la experiencia europea, especialmente el caso de Barcelona, cuyo modelo a pesar de las críticas, no deja de ser un referente permanentemente citado en círculos oficiales en los cuales sus promotores, particularmente aquellos con cartas credenciales académicas a la vez que ya vagamente de izquierda, han tenido una audiencia atenta y obediente.

La intervención estatal se ha dado bajo diversas estrategias: garantizar la seguridad del acceso a las áreas centrales, tanto incrementando las medidas de control y vigilancia física y electrónica (cámaras de vigilancia a la usanza de Londres) como estableciendo "perímetros seguros" a partir de una vigilancia acrecentada, la presencia de la fuerza pública y el mejoramiento de toda la infraestructura y el paisaje urbano (por medio de operaciones de rehabilitación de las fachadas, lo "visible"). Asimismo, los gobiernos locales han emprendido acciones directas de mejoramiento urbano, sea mediante inversiones en el patrimonio arquitectónico y los espacios públicos, como en ocasiones por medio de programas de recuperación de edificios para destinarlos al uso habitacional o a funciones culturales. En el caso latinoamericano, todavía es poco visible el paso de políticas de preservación y de conservación a unas de "herencia", tal como las describe Ashworth (2011), siguiendo entre otros a David Lowenthal, para el cual la política de herencia ("heritage") implica crear algo a partir de lo que nos deja el pasado. En el caso latinoamericano, se puede verificar una tendencia al estancamiento de las formas arquitectónicas y urbanas (sometidas a políticas estrictas de conservación, esencialmente) y no a la crea- ción de formas híbridas capaces de aliar el pasado con el presente.

Finalmente la intervención estatal se ha manifestado mediante la adopción de diversas modalidades de regímenes urbanos, los cuales se han ido construyendo mediante el acuerdo entre grupos de capital privado y políticos, los últimos manejando las justificaciones sociales y políticas de las intervenciones en los espacios centrales así como ejerciendo las inversiones recién mencionadas, mientras que los primeros cobran un lugar significativo en las inversiones productivas. Los sectores de intervención son diversos, desde la introducción de comercios de calidad, el desarrollo de la infraestructura hotelera y de restaurantes así como los servicios básicos ligados al desarrollo del turismo, $y$, finalmente, en una fase posterior, la intervención de programas de vivienda.

A partir de la predominancia de la economía de signos y espacio, tales como la definió Lash y Urry (1998), es entendible que la necesidad de expansión del posturismo originado en el capitalismo desorganizado ${ }^{6}$, solo puede resolverse en lugares donde sea posible que las nuevas formas de turismo sean compatibles los objetos y los imaginarios construidos sobre estos espacios.

Una de los aspectos más relevantes señalados por los mismos autores es que esta reflexividad estética es sustentada por las demandas de "cultura", "historia" y "ambiente" que forman ahora parte de los imaginarios de las sociedades occidentales avanzadas (Lash \& Urry, 1998: 344-345). Esto nos explica que más allá de las ventajas competitivas en la visión de un economista como Michael Porter, se pueda construir un mito del lugar (nuevamente en la expresión de los mismos autores) en torno a ciertos espacios como los centros históricos, en los cuales las dimensiones de cultura e historicidad son centrales

\footnotetext{
6 El posturismo se caracteriza por lo que los autores llaman una "reflexividad estética" por la cual los turistas ya no son simples consumidores, sino que se hacen diestros en la valoración de los lugares; buscan experiencias innovadoras y enriquecedoras con una aprehensión reflexiva de lo que les ofrecen, reflexiva en el sentido de potencialmente crítica (véase Lash \& Urry, 1998: particularmente 78-88)
} 
para alimentar los imaginarios de los posturistas. Estos imaginarios turísticos se vuelven entonces esenciales en la construcción del interés por el lugar "centro histórico". Son alimentados, entre otros, por las políticas de protección patrimonial que pretenden conferir un "aura" particular a diversos objetos arquitectónicos y urbanísticos distribuidos en el espacio central de las ciudades. El mito del lugar "centro histórico" no es más entonces que la configuración de un sistema de objetos y relaciones articulados entre sí por un aura producida tanto por la publicidad y diversos medios usados tanto por las autoridades como por los productores turísticos. Se trata de lo que podemos Ilamar, siguiendo a MacCannell (2007; 2012), la "imaginería turística" o, en otros términos, la construcción voluntarista de imaginarios difundidos entre consumidores para fines utilitaristas. Otra forma de denominar esta forma de trabajo sobre los imaginarios, pudiera ser la de "ingeniería imaginal" que hemos usado por otra parte (Hiernaux, 2012a).

Este complejo proceso que precisa de un tejido fino de políticas y acciones concretas constituye lo que ha sido denominado por Knafou y otros la "puesta en turismo" (M.I.T.) o según Marie-Françoise Lanfant la "turistificación" aplicada a los centros históricos (Lanfant, 1994).

Esta puesta en turismo buscará la producción de un entorno favorable a este posturismo, el cual requiere de una masa significativa de hoteles, restaurantes, eventos culturales y galerías de arte y tiendas de objetos representativos, entre otros, los cuales encuentran cabida en el espacio fragmentado y compuesto de estructuras de escalas pequeña o mediana, adaptables a esos usos nuevos y cargados del aura que les atribuye su historicidad: esto explica, entre otros, la boga actual de los "hoteles-boutiques" ubicados en estructuras arquitectónicas de pequeña escala, impensables en el marco del turismo de masa del capitalismo organizado, pronto a resolver por la gran escala las necesidades de los consumidores pasivos de su época ${ }^{7}$.

\footnotetext{
7 No se niega acá la existencia y la todavía enorme representación del turismo masivo en el turismo nacional e internacional; pero como fenómeno repre-
}

La gentrificación en las ciudades latinoamericanas puede entonces explicarse de una manera muy diferente de lo que ha ocurrido en las ciudades del mundo occidental avanzado. Por una parte, se pueden encontrar los efectos conocidos sobre la renta del suelo: no como rent gap, aunque no dudamos de su existencia como proceso bien real en la reconfiguración de ciertos centros históricos o ciertos espacios de los mismos, sino como reconfiguración del mercado de suelo. Tomando ciertas libertades hacia la ortodoxia del análisis marxista de la renta del suelo, se puede pensar de manera muy preliminar en la existencia de una renta diferencial del suelo, sustentada en el valor simbólico originado en la capacidad del mismo para responder a un uso potencial capaz de alimentar la reflexividad de los turistas actuales. En otros términos, no ligadas a la localización o las condiciones de infraestructura y entorno, sino a la interpretación que de esta porción específica del espacio se puede lograr a partir del tipo de visitantes.

Por otra parte, si bien se asiste a un incremento rápido de la renta del suelo por la puesta en turismo de parte o del conjunto del espacio central, es evidente también que la reapropiación del mismo por residentes potenciales de otro perfil que los actuales es y será mucho más selectiva tanto en capital cultural como en condiciones socioeconómicas. En otros términos, se realizará un retorno al centro de las ciudades sobre la base de contingentes de personas de mayores ingresos y capital. Esto diferencia sensiblemente las experiencias de la gentrificación residencial en países desarrollados de la que ocurre en países latinoamericanos entre otros, lo que, de paso, deja pensar, a manera de hipótesis, que la fase de llegada de "pioneros gentrificadores", como los denomina la literatura especializada será o menos intensa o de menos duración; remplazada casi inmediatamente por nuevos residentes de otro perfil, no tendrá lugar una transición más larga que

sentativo de la época actual, es con toda evidencia el posturismo y sus espacios singulares y propuestas diferenciadas entre sí que mejor describen las tendencias recientes, portadores de transformaciones sustanciales de las experiencias turísticas. 
pudiera tener la virtud de ser menos agresiva para los residentes tradicionales.

Los imaginarios vehiculados por los turistas y expresados a través de sus prácticas socioespaciales en el escenario urbano son suficientemente fuertes si no agresivos como para generar una confrontación cotidiana entre ellos y los demás grupos de "habitantes" de un centro histórico. En este sentido, valorizamos todas las críticas hechas en los setenta y ochenta sobre la relación visitante-visitado en la literatura anglosajona. Sin embargo, en vez de analizarla solamente como una marca de conflictividad social, la concebimos también como un inductor de cambios en los centros, en otros términos, como una forma conflictual de producir el espacio urbano; en ello asumimos la posición de Georg Simmel sobre la importancia del conflicto como variable explicativa de la dinámica social (Simmel, 1986).

Este tipo de cuestiones nos ha llevado, en un ensayo anterior, a hablar de "gentrificación criolla" es decir una denominación que distingue los procesos ya tradicionales y bien explicados de transformaciones inducidos por los recambios de población en espacios degradados del primer mundo, de aquellos que adquieren matices mucho más críticos en tanto que son más violentos frente a la población residente, en lo material como en lo simbólico.

Es tiempo ahora de retomar el tema, introducido en el segundo apartado de este ensayo, del turista como habitante de los centros históricos. Al respecto cabe advertir que la posición tradicional que distingue a los residentes de los turistas como actores totalmente distintos entre sí, proviene cronológicamente de una época de movilidad mucho menor de la población que lo que se vive en la actualidad. En este contexto, la diferencia entre residente tradicional y turista se basa en la no residencia permanente en el espacio y es vista como un factor discriminante, al considerar moralmente que el visitante no tiene los mismos derechos que un residente. Pero es preciso no perder de vista que es permanente la presencia del turista y más aún del posturista, sensible a las experiencias socioespaciales que le ofrecen el entorno central, aunque no resuelta por el mismo individuo, sino por una sucesión de individuos con características bastante genéricas y por ende con experiencias y prácticas sociales y espaciales bastante similares entre sí.

Al colocar al turista o al simple visitante como habitante aunque no residente permanente de los centros históricos, podemos entender ahora por qué razones los procesos de transformación en curso en los centros históricos latinoamericanos pueden ser considerados como una forma particular de gentrificación, razón más para consagrar la propuesta nuestra de hablar de una "gentrificación criolla". El visitante es entonces un agente de "producción del espacio" en términos de Lefebvre (1974). La producción que realiza puede ser tanto material, como por ejemplo cuando él adquiere una construcción y la transforma en residencia temporal, como simbólica cuando marca el espacio a partir de sus intereses, su estilo de vida, etc. Así, la valorización que hace el turista de un sitio particular, sea por un interés genuino sea llevado a ello por la publicidad turística, le otorga una suerte de aura a un sitio que no lo tiene forzosamente en el marco de la vida cotidiana de los residentes ${ }^{8}$.

Quizás una de las formas más genuinas y posiblemente desconocida de ellos mismos por la cual los turistas redefinen los espacios centrales, es su aporte al flujo sensible “...de signos e imágenes que saturan la fábrica de la vida cotidiana en la sociedad contemporánea" (Featherstone, 1996: 270). Estos signos son, en primer lugar, vehiculados por los turistas mismos y producen el espacio simbólico: un mirada diferente al espacio (en

\footnotetext{
8 Nos referimos por ejemplo al caso de puesta en valor de la casa de un personaje ilustre, la cual, para quienes residen alrededor quizás no tenía sentido o, peor, ni conocían la persona mencionada. A manera de ejemplo, el Instituto Nacional del Audiovidual de Francia ha producido y difundido varios programas televisivos sobre "los lugares de Marguerite Duras". Lo anterior ha propiciado un interés creciente de turistas para visitar estos lugares (Duras y Porte, 2012). Por otra parte, podemos mencionar que una emisión televisiva francesa de 2009, ("Des Racines et des Ailes") ha tenido un papel considerable en el incremento exponencial del flujo de turistas en los pasajes cubiertos parisinos, los cuales se situaban antes fuera de la terra cognita de la gran mayoría de los mismos.
} 
el sentido del "gaze" usado por Urry) que distrae la manera tradicional del residente de leer su propio espacio (desprecio por ciertos espacios cotidianos del residente; insistencia que satura sobre algunos espacios cubiertos por un "aura" invisible para el residente pero evidente para el turista, etcétera); participación a la creación de nuevos espacios de intercambio entre turistas, de los cuales los residentes no son físicamente excluidos pero sí mantenidos simbólicamente a distancia, como cafés de franquicia y otros mecanismos diversos. No se trata que el turista sea responsable de todo como persona, sino que sus expectativas con relación a un espacio determinado son desmenuzadas y recuperadas por los productores de espacios y servicios turísticos que actúan para los turistas, para generar estos signos a lo largo y ancho del espacio. Es en ese sentido que Fox Gotham señala que la creación y reproducción de una imagen de un destino, requiere de un sistema institucional o de un conjunto de organizaciones formales (Fox Gotham, 2008). En las ciudades latinoamericanas así como en muchas más, este conjunto integra organizaciones oficiales locales y centrales, asociaciones de prestadores de servicios, cámaras locales, etcétera. Se trata claramente de un conjunto de actores que producen el destino, en nuestro caso, una imagen de los centros históricos, fuertemente articulada con una imagen general de la ciudad ${ }^{9}$. Al respecto, vale notar la relevancia de la cartografía turística que integra y permite reconocer las ambigüedades mismas de la producción del espacio turístico como lo señalan Del Casino y Hanna (2000). Lo mismo puede ser dicho de la producción de guías turísticas, los cuales también determinan para el turista lo que debe ser visto, cómo debe ser interpretado y qué significado se le puede asignar. Pensamos muy particularmente en la guía francesa "Bobo" Le guide

\footnotetext{
9 Para el caso de Querétaro, la imaginería producida por ese conjunto de organizaciones / grupos de interés, maneja un discurso uniforme que incluye la ciudad en su totalidad (por ejemplo con el lema "Suertudo tú que vives en Querétaro") al mismo tiempo que promueve sus "maravillas turísticas". En otras ciudades del interior del país se debe desligar la imagen turística de la situación general de la ciudad, por el contexto crítico de violencia ligado al narcotráfico y a la delincuencia organizada en general (caso de Morelia y Zacatecas, entre otras).
}

du Routard, de la cual encontramos una crítica acérrima en la novela Plataforma de Michel Houellebecq (2002).

Posiblemente sea ahora tiempo de presentar una valoración del término de "turista" en sí: como bien lo señala Crouch (1999), en las sociedades actuales, estas mismas que fueron calificadas antes como resultado del capitalismo desorganizado, resulta complejo distinguir al turista de otro visitante. Por una parte, es difícilmente realizable una distinción entre turista (el que en principio "no trabaja") del viajero por fines profesionales que aprovecha la estancia laboral para darse un "baño de ciudad". Por otra parte y en la medida misma que las estancias cortas se multiplican, los turistas se parecen más a residentes suburbanos de visita al centro de la ciudad. El prototipo de turista como aquel presente en las películas de Jacques Tati, es difícilmente observable salvo en los destinos de gran afluencia. Crouch propone entonces de hablar de "tourism/leisure", una dupla de turismo y ocio que permite incluir en una misma categoría, turistas, excursionistas, o los mismos habitantes de paseo por su ciudad. Esta observación es tanto más valiosa que los comportamientos suelen ser muy similares entre los diversos grupos.

En este contexto, no solo pretendemos analizar el papel del turista como habitante, sino también aquel que ejercen las empresas capitalistas que sacan provecho de esta situación y transforman el espacio urbano por medio de inversiones en estructuras de alojamiento, restaurantes, etcétera. Un capital por lo demás fuertemente estimulado y sustentado por políticas de imagen de marca ("branding") y de competitividad urbana por los gobiernos locales.

Otro punto importante es la interrogante de saber si los espacios apropiados por los turistas son espacios sujetos a gentrificación. En este sentido, la literatura sobre el tema del espacio turístico ha insistido sobre el concepto de "distrito" (Pearce, 1999) y el de "recinto" turístico (precint, tal y como lo definen Hayllar et al., 2008: 3-18). Ambos términos reflejan una cierta visión predeterminada sobre el espacio recorrido por el turista. Es cierto, y se comprueba fácilmente en los estudios de campo, que por diversos motivos los tu- 
ristas suelen concentrarse en determinados espacios, por lo que se puede efectivamente hablar de recinto. Sin embargo, es notorio que los posturistas, aquellos que no siguen de manera cumplida las sugerencias de las guías y mapas turísticos, desbordan los límites del recinto y parten de "exploración". Movidos por una voluntad de explorar/descubrir más allá de lo normalizado, definen una aureola en torno al espacio turístico previsible, una suerte de espacio intermedio.

Nuestra observación al respecto es que el recinto suele ser el espacio donde las actividades turísticas en sí, con intervención de capitales orientados claramente al turismo, transforman más radicalmente el espacio urbano: se trata de espacios donde aparecen signos que demuestran claramente la presencia de un capital turístico y de eventuales gentrificadores. Es también el espacio del mayor conflicto con los residentes, donde los efectos perversos de la gentrificación son más transparentes a la mirada del observador. Sin embargo, la aureola que rodea el recinto, pudiera ser, en nuestra experiencia, un espacio donde la gentrificación se ejerciera de manera más tradicional, es decir por intervenciones puntuales de compradores de viviendas, con la instalación de negocios de menor calidad pero progresivamente orientados por la demanda turística, o la transformación de negocios tradicionales de residentes hacia la atención a esa demanda potencial: en otros términos, una gentrificación más conforme a los patrones de progresividad analizados en la literatura del caso. Esa corona exterior corre con toda evidencia el riesgo de ser alcanzada por los espacios formalizados por la gentrificación turística, con la consabida transformación de su paisaje y aprovechamiento ${ }^{10}$. Bien podrá entonces integrarse

\footnotetext{
10 En el caso de la ciudad de Querétaro que estamos estudiando, el recinto turístico es de tipo lineal, correspondiente a un sistema de plazas articuladas por conexiones peatonales que el gobierno municipal pretende consolidar como "corredor turístico" (González, 2012: 129-149). En el extremo Este, de mayor altitud, en torno a la plaza Fundadores se ubica en el Barrio de la Cruz que estudiamos actualmente. En torno a la plaza, todavía no se dibuja bien el "recinto". Existe sin embargo un espacio de aureola, de transición, tanto por la presencia de nuevos negocios ligados a una evidente gentrificación, como
}

después en la terra cognita de los turistas posteriores.

Falta por realizar unos comentarios sobre los posibles conflictos que emergen de ese encuentro entre espacios de vida habituales de los residentes y las prácticas ejercidas por los turistas sobre los mismos espacios. En esta parte del análisis, recurriremos a ciertos aportes de autores como David Harvey cuando habla de "acumulación por desposesión" (Harvey, 2004) que aparece como el mecanismo central por el cual el capital en turismo se hace de las estructuras físicas y de los espacios de vida de los habitantes tradicionales para desarrollar sus actividades, expulsándolos; también planteamos la posibilidad de usar la expresión para referirnos a la manera como el turismo desposee a los residentes de un género de vida histórico con la finalidad de acumular experiencias nuevas para su propia cotidianidad.

La esencia de este conflicto proviene, en nuestro entender, de una diferencia fundamental de percepción de los bienes y servicios entre los grupos residentes y los grupos de turistas. Quizás ilustre bien este planteamiento, la discrepancia entre BrillatSavarin y Baudelaire recordada por Douglas e Isherwood. Mientras que el autor del primer tratado de gastronomía calificaba al vino como elemento nutricional, el poeta lo engrandecía como fuente de "...memoria y olvido, felicidad y melancolía" (Douglas e Isherwood, 1990: 89). Esta alegoría puede reflejar el hecho de que mientras el turista observa o acumula objetos y espacios como "nutrición turística", el residente los valora como parte esencial de su condición de seren-el-mundo. Posiblemente nos acusen de fundamentalismo, ya que muchos turistas alimentan su memoria y su felicidad con la

\footnotetext{
de viviendas transformadas por personas ajenas a la comunidad barrial tradicional. La delimitación de estos dos espacios, es un proceso que realizamos en la actualidad, con el entendido que es un espacio cambiante que exige un seguimiento para entender su dinamismo. Vale notar que esta observación también es válida para la ciudad de México, donde la gentrificación de tipo tradicional se extiende en un espacio externo al recinto de mayor gentrificación aunque contiguo al espacio remodelado por las políticas públicas.
} 
contemplación de sitios, la compra de recuerdos o el alojamiento en ciertos lugares de calidad no homogeneizados por el capital, pero la metáfora es útil para marcar la distinción entre el sentido mismo de todo lo que se encuentra en el recinto turístico: podemos recurrir aquí a la noción de fantasía como la define Slavoj Žižec, la cual se realiza "...en un escenario fantástico que opaca el horror de la situación" (Žižec, 1999: 15). Como demuestra el autor, la fantasía nos permite ver lo que nos rodea como un todo orgánico sin ver los antagonismos que recorren nuestra sociedad; es un esquematismo de lo que realmente ocurre. La fantasía deforma la mirada del turista, el cual, además, no está preparado para leer los signos que contiene el espacio que recorre y que han sido construidos consensual o antagónicamente por los residentes. Por lo mismo, son los signos que provienen de los mismos turistas (el discurso sobre las vacaciones, las fotos, los souvenirs, las compras efectuadas, la renovación de la fachada de la segunda residencia en centro histórico...) o que los capitales turísticos riegan de manera abundante sobre el espacio, los que otorgan el sentido que requieren los turistas para visitar y consumir el lugar de manera serena.

Sin embargo, estos signos son agresivos para el lector-residente; por ello mismo pueden sentirse incómodos y reaccionar de manera fuerte contra los invasores: esto es lo que explica una pinta vista años atrás en una pared del Barrio Gótico de Barcelona: "Tourist, you are the terrorists". Si bien la comparación entre turistas y terroristas es "algo" exagerada, refleja el enojo, la sensación de ser violentados por esta turistification que transforma, gentrifica el espacio de los residentes.

\section{El turista gentrificador: a manera de síntesis}

Para entender la relación entre el turismo y la gentrificación fue necesario, en un primer tiempo, replantear lo que es y no es el turismo urbano. En ese contexto, hemos dejado de lado las posibles reflexiones que se derivan de los grandes proyectos turísticos urbanos, como aquellos descritos en Díaz Orueta y Fainstein (2009) y Sassen y Roost (1999); entre otros: Museos, centros depor- tivos, atención a Olimpiadas y festivales, rehabilitación de frentes fluviales quedaron así fuera de nuestro planteamiento si bien merecen atención en ciertos contextos nacionales.

La posibilidad de repensar el turismo más allá de un simple consumo sino desde una perspectiva que estudie y valorice el papel del turista-individuo actante, que entienda los espacios turísticos como loci de políticas de consolidación de marca de ciudad, como espacios de juego y al nuevo prototipo de visitante como posturista es decir alguien con mayor capacidad de reflexividad, fueron algunos de los ejes centrales de la reflexión.

Aplicando estas propuestas recogidas de orígenes epistemológicas diversas, permite dar una lectura a la relación del turismo urbano con los espacios centrales de las ciudades, así como iniciar unas reflexiones sobre la relación entre ese turismo y los procesos de gentrificación. Para avanzar en los planteamientos sobre el tema, hemos insistido en un primer tiempo en la trayectoria histórica de los centros urbanos latinoamericanos, la mayor parte de los cuales han transitado de una ocupación socialmente mezclada aunque marcada por una segregación normalizada en la época colonial, hacia un abandono a los sectores populares. Proceso que, en la actualidad, inicia su reversión por el nuevo interés del capital y de las clases dominantes sobre el citado espacio.

Posteriormente hemos hecho la aclaración que ser turista en un lugar determinado es una de las formas de habitar, por lo que un estudio comprehensivo de la relación posible entre turismo y gentrificación, debe ignorar las posturas que diferencian en exceso los residentes de los no residentes. Justamente esta forma de pensar al turista o al visitante como habitante (para evitar también una diferenciación que no tiene ya curso según Crouch) nos permite también pensar que los conflictos surgirán no de ese paso momentáneo del turista sobre el espacio central de la ciudad, sino como un conflicto de apropiación a mediano y largo plazo.

Este conflicto de apropiación lo hemos ligado directamente al hecho de que el turistahabitante produce el espacio, particularmente por medio de la producción y apropiación de 
signos aunque también en la dimensión material del espacio. A ello hemos agregado que el espacio es también modelado por el papel de la publicidad y de mecanismos de difusión de imágenes de destino, gracias a una verdadera imaginería del destino, construida por el capital y por todo un sistema de organizaciones públicas.

El espacio donde se da el proceso turístico es, sin lugar a duda, un espacio en vía de gentrificación, pero bajo un modelo "criollo" ya que la gentrificación no la realizan tanto las clases pudientes locales como en el modelo clásico, sino habitantes no residentes: los turistas. Lo anterior sin excluir que fuera del recinto turístico, en una suerte de aureola en torno al mismo que se atreven a explorar algunos posturistas, pueda darse un gentrificación tradicional sustentada en el cambio de giros comerciales operados por los propios residentes o en la inserción progresiva de segundas residencias o de gentrificadores locales, entre otros.

En el recinto gentrificado, abundan los conflictos pero estos no son solo los que han registrado los textos ahora ya clásicos sobre la gentrificación: expulsión de residentes tradicionales, encarecimiento de la renta del suelo entre otros. Pensamos que se asiste a una guerra de signos enraizada en la oposición entre el sistema de espacios, objetos y signos que sustentan la vida cotidiana de los residentes versus la construcción fantasiosa de los turistas que ejercen otra lectura del espacio barrial; esta guerra facilita, define y perenniza los mecanismos de gentrificación. Esta lectura más sustentada en el reconocimiento de la subjetividad de los actores en juego (residentes, turistas-habitantes y organizaciones de capital o públicas) que en la materialidad de los procesos en curso, se traduce y es también alimentada por esta materialidad y las consecuencias sociales no dejan de ser las que expresa la literatura sobre el caso (Delgadillo, 2009).

Para avanzar sobre estas propuestas originadas en el conocimiento de algunas situaciones concretas, un trabajo sistemático de comparación entre casos se antoja necesario porque dará pistas, sin duda alguna, para reforzar los planteamientos que pudieran volverse los sustentos de la construcción de una epistemología propia a los casos latinoamericanos, sobre estos procesos tanto en su dimensión turística como de gentrificación, las cuales, en nuestra opinión como autores, están radicalmente imbricadas en un modelo diferente pero consistente de gentrificación.

\section{Referencias bibliográficas}

ASHWORTH, G. Preservation, Conservation and Heritage: Approaches to the Past in the Present through the Built Environment. Asian anthropology, 2011, N 10, p. 1-18.

BALSLEV, H. y VELÁZQUEZ, M. La posición social y espacial en una ciudad turística. Las luchas simbólicas de Álamos, Sonora. PASOS. Revista de Turismo y Patrimonio Cultural, 2010, Vol. 18, N¹, p. 47-59.

BERDOULAY, V. El sujeto, el lugar y la mediación del imaginario. En: LINDON, A. y HIERNAUX, D. (directores). Geografías de lo imaginario. Barcelona: Anthropos y Universidad Autónoma Metropolitana Iztapalapa, 2012b, p.49-64.

BERQUE, A. Qu'est-ce que l'espace de I'habiter? In: PAQUOT, T.; LUSSAULT, M. \& YOUNES, C. (editors). Habiter, le propre de I'humain. Villes, territoires et philosophie. Paris: La Découverte, 2007, p. 53-66.

COHEN, E. A phenomenology of tourist experiences. Sociology, 1979, Vol. 13, p. 179-201.

CROUCH, D. Leisure/tourism geographies. Practices and Geographical Knowledge. Nueva York: Routledge, 1999.

DA SOUZA SANTOS, B. Una epistemología del Sur. México D.F.: Clacso Coediciones Siglo XXI, 2009.

DE RADKOWSKI, G-H. Anthropologie de I'habiter: Vers le nomadisme. Paris: Presses Universitaires de France, 2002.

DEBORD, G. La sociedad del espectáculo. Buenos Aires: La Marca, 1995.

DEL CASINO, V. \& HANNA, S. Representations and identities in tourism map spaces. 
Progress in Human Geography, 2000, № 24, p. 23-46.

DELGADILLO POLANCO, V. Patrimonio urbano y turismo cultural en la ciudad de México: Las Chinampas de Xochimilco y el centro histórico. Andamios, 2009, № 6, p. 69-94.

DÍAZ ORUETA, F. \& FAINSTEIN, S. The New Mega-Projects: Genesis and Impacts. International Journal of Urban and Regional Research, 2009, No 32, p. 759-767.

DOUGLAS, M. y ISHERWOOD, B. EI mundo de los bienes. Hacia una antropología del consumo. México, D.F.: Consejo Nacional para la Cultura y las Artes y Grijalbo, 1990.

DURAS, M. \& PORTE, M. Les lieux de Marguerite Duras. Paris: Les éditions de Minuit, 2012.

EQUIPE MIT (editors). Tourismes 1 Lieux communs. Paris: Editions Belin, 2002.

EQUIPE MIT (editors). Tourismes 2. Moments de lieux. Paris: Editions Belin, 2005.

EQUIPE MIT (editors). Tourismes 3. La Révolution Durable. Paris: Editions Belin, 2011.

FAINSTEIN, S. \& GLADSTONE, D. Evaluation Urban Tourism. In: JUDD, D. \& FAINSTEIN, S. (editors). The tourist City. London: Yale University Press, 1999, p. 21-34.

FAINSTEIN, S. \& JUDD, D. Cities as Place to Play. In: JUDD, D. \& FAINSTEIN, S. (editors.). The tourist city. London: Yale University Press, 1999, p. 261-272.

FeAtherstone, M. Postmodernism and Aestheticization of Everyday Life. In: LASH, S. \& FRIEDMAN, J. (editors). Modernity and Identity. Oxford \& Cambridge, USA: Blackwell, 1996, p. 265-290.

FLORIDA, R. The Rise of the Creative Class. And How is Transforming Work, Leisure, Community and Everyday Life. New York: Basic Books, 2002.

FOX GOTHAM, K. Destination New Orleans: Commodification, rationalization, and the rise of urban tourism. Journal of Consumer Culture, 2007, № 7, p. 305-334.

GIGLIA, A. El Habitar y la cultura. Perspectivas teóricas y de investigación. BarceIona: Anthropos y Universidad Autónoma Metropolitana Iztapalapa, 2012.

GLADSTONE, D. \& HOFFMAN, L. Research Planning Group on International Tourism and Urban Restructuring in Comparative Perspective, 1998. International Journal of Urban and Regional Research, 2008, № 22, p.674-675.

GONZÁLEZ, C.I. Las plazas públicas, reducto del ocio vecinal. En: HIERNAUX, D y GONZÁLEZ, C.I. (editores). Espacio-temporalidad y prácticas sociales en los centros históricos mexicanos. Querétaro: Universidad Autónoma de Querétaro, 2012, p.129-149.

HARVEY, D. El 'nuevo' imperialismo. Acumulación por desposesión. Socialist Register, 2004, No 42, p. 99-129.

HAYLLAR, B.; GRIFFIN, T. \& EDWARDS, D. Urban tourism precincts: engaging with the field. In: HAYLLAR, B.; GRIFFIN, T. \& EDWARDS, D. (organizers.). City spaces-tourist places: urban tourism precincts. Oxford: Butterworth-Heinemann, 2008, p. 3-18.

HIERNAUX, D. (editor) Las segundas residencias en México: un balance. México: Universidad del Caribe-Universidad Autónoma del Estado de México y Plaza y Valdés, 2010.

HIERNAUX, D. Competitividad de las ciudades turísticas de México en el contexto global. En: ARCE, C.; CABRERO, E. y ZICCARDI, A. (coordinadores). Ciudades del Siglo XXI: ¿Competitividad o Cooperación? México: H. Cámara de Diputados LIX Legislatura \& CIDE, 2005, p. 609-639.

HIERNAUX, D. Habitar un mundo globalizado. Veredas, Revista de Ciencias Sociales, 2012a, Año 13, No 25, p. 7-25.

HIERNAUX, D. La geografia del turismo. En: HIERNAUX, D. y LINDÓN, A. (Directores). Tratado de geografía humana. Barcelona: Anthropos editores y Universidad Autónoma Metropolitana Iztapalapa, 2006, p. 397-428. 
HIERNAUX, D. Los imaginarios urbanos. Una aproximación desde la geografía urbana y los estilos de vida. En: HIERNAUX, D. y LINDON, A. (directores). Geografías de lo imaginario. Barcelona: Anthropos y Universidad Autónoma Metropolitana Iztapalapa, 2012b, p. 87-105.

HIERNAUX, D. Mineral de Pozos. Where amenity Tourists recreates Mexican Identity. In: MOSS, L.A.G. \& GLORIOSO, R.S. (editores). Global Amenity Migration. Transforming Rural culture, Economy and Landscape. Inprint, 2014.

HOFFMAN, L.; FAINSTEIN, S. \& JUDD, D. (editors). Cities and visitors, regulating people, markets, and city space. Malden, USA: Blackwell Publishing, 2003.

HOUELLEBECQ, M. Plataforma. Madrid: Anagrama, 2002.

JANOSCHKA, M.; SEQUERA, J. \& SALINAS, L. Gentrification in Spain and Latin America - a Critical Dialogue. International Journal of Urban and Regional Research, 2013, Vol. 38, No 4, p. 1234-1265.

JANSEN-VERBEKE, M. Touristification of historical cities. Annals of Tourism Research, 1998, Vol. 25, No 3, p. 739-742.

JUDD, D. \& FAINSTEIN, S. (editors). The tourist city. London: Yale University Press, 1999.

JUDD, D. (editor). The Infraestructure of Play. Building the Tourist City. New York: M.E. Sharpe, 2003.

JUDD, D. El turismo urbano y la geografía de la ciudad. EURE, 2003, Vol. 39, №87, p. 51-62.

LANFANT, F. Identité, mémoire et la touristification de nos sociétés. Sociétés. Revue des Sciences Humaines et Sociales, 1994, No 46, p. 433-439.

LASH, S. y URRY, J. Economías de signos y espacio. Sobre el capitalismo de la posorganización. Buenos Aires: Amorrortu editores, 1998.
LEES, L.; SLATER, T. \& WYLY, E. Gentrification. New York: Routledge, 2008.

LEFEBVRE, H. La production de l'espace. París: Anthropos, 1974.

LLOYD, R. Neobohemia: art and neigborhood redevelopment in Chicago. Journal of Urban Affairs, 2002, N²5, p. 517-532.

MacCANNELL, D. El turista. Una nueva teoría de la clase ociosa. Madrid: Melusina, 2003.

MacCANNELL, D. La imaginación frente al imagineering. En: V.V.A.A. Imaginarios urbanos en América Latina: urbanismos ciudadanos. Barcelona: Fundación Antoni Tapiès, 2007, p. 169-178.

MacCANNELL, D. Los dos imaginarios. En: HIERNAUX, D. y LINDÓN, A. (directores). Geografías de lo imaginario. Barcelona: Anthropos y Universidad Autónoma Metropolitana Iztapalapa, 2012, p. 107-116.

MULLINS, P. Class relations and tourism urbanization: The regeneration of the petite bourgeoisie and the emergence of a new urban form. International Journal of Urban and Regional Research, 1994, Vol. 4, Nº 18, p.591-608.

MULLINS, P. Tourism Urbanization. International Journal of Urban and Regional Research, 1991, Vol. 3, №15, 1991, p. 362-342.

NATES CRUZ, B. y RAYMOND, S. Buscando la naturaleza. Migración y dinámicas rurales contemporáneas. Barcelona: Anthropos, 2006.

PAQUOT, T.; LUSSAULT, M. \& YOUNES, Ch. Habiter, le propre de l'humain. Villes, territoires et philosophie. Paris: La Découverte, 2007.

PEARCE, D.G. Tourism in Paris: Studies at the Microscale. Annals of Tourism Research, 1999, Vol. 1, No 26, p. 77-97.

PORTER, M. The Competitive Advantage of Inner City. Harvard Business Review, 1995, mayo-junio, p. 55-71. 
ROMERO, J.L. Las ciudades y las ideas. Buenos Aires: Siglo XXI Editores, 1976.

SIMMEL, G. El Individuo y la Libertad (Ensayos de la crítica de la Cultura). Barcelona: Ediciones Península, 1986.

STOCK, M. Habiter touristiquement la ville. In: DUHAMEL, P. (editor). Mondes Urbains du Tourisme. París: Belin, 2007, p. 25-28.

TARRIUS, A. Les fourmis d'Europe : migrants riches, migrants pauvres et nouvelles villes internationales. París: L' Harmattan, 1992.
URRY, J. The Tourist Gaze. Londres: SAGE, 2002.

URRY, J. Sensing the City. In: JUDD, D. \& FAINSTEIN, S. (editors). The tourist city. London: Yale University Press, 1999, p. 71-88.

WHITE, L. \& FREW, E. (editors). Dark tourism and place identity: managing and interpreting dark places (contemporary geographies of leisures, tourism and mobility). London: Routledge, 2013.

ŽlŽEK, S. El acoso de las fantasías. México: Siglo XXI, 1999. 